\title{
Proposal for a Special Interest Group in Lesbian and Gay Mental Health
}

\section{Procedure for establishing a Special Interest Group}

(a) Any member wishing to establish a Special Interest Group shall write to the Registrar with relevant details.

(b) The Registrar shall forward the application to Council.

(c) If Council approves the principle of establishing such a Special Interest Group then it will direct the Registrar to place a notice in the Psychiatric Bulletin, or its equivalent, asking members of the College to write in support of such a Group and expressing willingness to participate in its activities.

(d) If at least 120 members reply to this notice, then Council shall formally approve the establishment of the Special Interest Group.

In accordance with this procedure, Council has approved the establishment of a Special Interest Group in Lesbian and Gay Mental Health, to provide a focus for discussion and research and to serve as a source of expertise within the College in this area. It is also anticipated that the Special Interest Group would make an important contribution to public education. The principal issues with which the Special Interest Group would be concerned would include:

(a) access to mental health care;

(b) attitudes within the health service to homosexuality;

(c) the relationship between bullying and discrimination of young gay and lesbian people and suicide and deliberate selfharm;

(d) substance misuse among the gay and lesbian communities;

(e) the difficulties experienced by gay and lesbian health professionals in the workplace.

Members are invited to write in support of this Group and express willingness to participate in its activities. Interested members should write to Miss Sue Duncan at the College. If 120 members reply to this notice, then Council shall formally approve the establishment of this Special Interest Group.

MiKe SHOOTER, Registrar, Royal College of Psychiatrists, 17 Belgrave Square, London SW1X 8PG 